\title{
'ARE USA'S AND CHINA'S ARTIFICIAL INTELLIGENCE ACTIVITIES OUTSMARTING EUROPE?' - A CRITICAL ANALYSIS OF AI AND EUROPE'S APPROACH TO IT.
}

\author{
Christina F. Edye, Chair of Mobility, Trade and Logistics, Zeppelin University, Germany
}

Wolfgang H. Schulz, Chair of Mobility, Trade and Logistics, Zeppelin University, Germany

\author{
dx.doi.org/10.18374/EJM-20-1.8
}

\begin{abstract}
Artificial Intelligence (Al) is vital for nations and their national industries to remain competitive in the world of digitalization and to ensure growth, employment and overall welfare. Al in the field of transportation would result in benefits for individual drivers, other participants in traffic, as well as process advances for manufacturers and suppliers. Further, a domino effect for society as a whole could be created. This paper explores the European Union's approach to Al, and the road blocks it is currently facing, including analyzing its competitors. Al data does not follow classic economic theories. Here, scarcity is no longer the rule, instead the larger the data sets and information provided, the higher their value. This provides China (large population) and USA (capital resources) with key advantages, due to their ease of generating data, or does it? While the European Commission wants to invest $€ 20$ billion to expand Al in the European Union, it has to tackle several issues for Al to be truly effective. One issue is that the union's nations must act together to generate data sets large enough to compete with China and USA. Further, AI built into vehicles will need to be 'smarter' compared to foreign vehicles, to enable handling the complexity of different driving behaviors upon border crossing. While it may take longer to expand $\mathrm{Al}$ in Europe, the broader knowledge required could become Europe's advantage for catching up with its competitors.
\end{abstract}

Keywords: artificial intelligence, competition, development, automotive, Al productivity 